Millikan has in his own experiment assumed a value for the viscosity of air at $23^{\circ} \mathrm{C}$. of $(1822.6 \pm 0.04 \times$ $10^{-7}$ c.G.s. units, which is based only on the observations of Harrington ${ }^{5}$.

Various experimenters have measured the viscosity of air, obtaining results varying from $1820 \times 10^{-7}$ to $1850 \times 10^{-7}$. In view of the importance of an accurate knowledge of the coefficient of viscosity, we have carried out an investigation on viscosity from flow through capillary tubes. For the purpose of measuring instantaneous values of pressures, a method based on the counting of interference fringes originally adopted by Wagstaff ${ }^{6}$ was employed with improvements. Five different capillary tubes were used and various necessary corrections were applied. The final value of viscosity of dry air at $23^{\circ} \mathrm{C}$. obtained by us is $(1833 \cdot 3 \pm 2 \cdot 1) \times 10^{-7}$ c.G.S. units, while the increase per degree centigrade is $4.95 \times 10^{-7}$ c.G.s. units. Our value is essentially close to Kellström's value $(1834.9 \pm 2.7) \times 10^{-7}$ and also to Bond's value $(\mathbf{1 8 3 4 \cdot 7} \pm 0 \cdot 8) \times 10^{-7}$. Rigden ${ }^{8}$ has reported a slightly lower value.

If our value of viscosity of air be substituted in Milli. kan's oil drop experiment, $e=(4 \cdot 811 \pm 0 \cdot 009) \times 10^{-10}$ E.S.U., which agrees with the $\mathrm{X}$-ray value of $e=4 \cdot 807 \times 10^{-10}$ within the source of experimental error.

A detailed account of the work will be published elsewhere.

\footnotetext{
Department of Physics, Ravenshaw College, Cuttack.

1 Bearden, Phys. Rev., 37, 1210 (1931).

'Bäcklin, Z. Phys., 83, 450 (1934).

s Birge, Phys. Rev., Supp., 1, 1 (1929).

4 Millikan, Phil. Mag., 34 (1917).

5 Harrington, Phys. Rev., 8, 738 (1916).

- Wagstaff, Phil. Mag., 45, 84 (1923).

' Kellström, Phil. Mag., 23, 250 (1937).

Bond, Proc. Phys. Soc., 49, 206 (1937).

- Rigden, NATURE, 141, 82 (Jan. 8, 1938).
}

G. B. BanerJea.

B. Pattanaik.

\section{Life-History of the Salmon (Salmo salar L.)}

IN a recent communication, published in The Times of March 26, we appealed to British and Irish boards of salmon fisheries for help in obtaining material for the study of the sexual phases in salmon parr; we now wish to appeal to all European bodies who could send us samples of either salmon parr or salmon smolts five inches in length or more.

We have found that a ripe and almost certainly functional male phase is attained normally in mostand possibly all-male Salmo salar from the Welsh and Cheshire Dee before they migrate to the sea as smolts ${ }^{1}$. To obtain evidence of the functionality of this phase it is necessary to examine parr or smolts in the post-breeding season. Material from the Welsh Dee has confirmed the inference that the young males spawn in this river; a full account of this work will be published elsewhere later. It is, however, desirable to investigate the problem throughout the geographical range of the salmon to ascertain whether the phase is constant under widely different environmental conditions.

It is conceivable that breeding habits may vary in this fish with extremes of habitat. The results from the Dee indicate that spent males may behave differently from the mature females of the same age, whence it is advisable to sample different groups or shoals of parr or smolts. Such samples from European countries would be gratefully received and gladly acknowledged by us at the address given below, and reasonable expenses paid.

\section{J. H. ORTON.}

J. W. Jones.

Department of Zoology,

University of Liverpool.

1 Orton, J. H., Jones, J. W., and King, G. M., Proc. Roy. Soc., B, 125, No. 898 (March 1938).

\section{Revision of $\mathrm{Al}$ I Terms}

IN the course of a study of the proper co-ordination of the $\mathrm{AlH}$ spectral terms to the $\mathrm{Al}+\mathrm{H}$ atomic combinations ${ }^{1}$, some doubts arose as to the correct. ness of Lansing's analysis ${ }^{2}$ of the $\mathrm{Al} \mathrm{I}$ lines in the region 3050-3070 A. Spectrograms of an interrupted aluminium arc were taken with the large concave grating of this Institute. The measurement of the seven lines (three of which were attributed by Lansing, on the basis of wrong measurements, to an $s p^{2}{ }^{2} D \rightarrow s^{2} p{ }^{2} P$ transition) revealed, first, that no one wave-number difference is equal to the separation of the $s^{2} p{ }^{2} P$ ground state of Al, and secondly, that all the seven observable lines can be explained at once by a $3 s 3 p 4 s{ }^{4} P \rightarrow 3 s 3 p^{2}{ }^{4} P$ transition. This explanation is supported by the analogous termcombinations in the isoelectronic sequence $\mathrm{Al}$ I, Si II, etc. $^{3}$; the separations of the multiplet components and relative positions of the two ${ }^{4} P$ terms of $\mathrm{Al}$ can be calculated to a rather good approximation from the positions and separations of the related terms. Preliminary results of Zeeman effect experiments on the strongest of the seven lines involved also confirm the ${ }^{4} P \rightarrow{ }^{4} P$ explanation.

The classification, wave-numbers and estimated intensities of the analysed group of seven $\mathrm{Al}$ I lines are given in the following table:

\begin{tabular}{|c|c|c|c|c|}
\hline & & & $383 p 48$ & 4 \\
& & $j=5 / 2$ & $j=3 / 2$ & $j=1 / 2$ \\
\hline $3 s 3 p^{2} \cdot P$ & $j=5 / 2$ & $\begin{array}{c}32700 \cdot 6 \\
(10)\end{array}$ & $\begin{array}{c}32604 \cdot 6 \\
(8)\end{array}$ & - \\
& $j=3 / 2$ & $\begin{array}{c}32776 \cdot 5 \\
(6)\end{array}$ & $\begin{array}{c}32680 \cdot 4 \\
(2)\end{array}$ & $\begin{array}{c}32624 \cdot 1 \\
(3) \\
\end{array}$ \\
& $j=1 / 2$ & - & $\begin{array}{c}32727 \cdot 1 \\
(4)\end{array}$ & $\begin{array}{c}32671 \cdot 0 \\
(0)\end{array}$ \\
\hline
\end{tabular}

Since the incorrect previous assignment has been quoted in books of reference (such as "Atomic Energy States" by Bacher and Goudsmit), a revision, that is, the dropping of the term-value of $3 s 3 p^{2}{ }^{2} \mathrm{D}$, seems to be necessary. One gains, however, a more uniform co-ordination (in the sense already outlined ${ }^{1}$ ) of the hydride and deuteride molecular terms of the elements in the third column of the Periodic Table with the proper atomic term-combinations.
R. SCHMID.
L. GERö.
Katalin LöRINCZI.
G. NEU.

Physical Institute, Royal Hungarian

University for Technical and Economic Sciences, Budapest. April 21.

1 Schmid and Gerö, Naturwiss., 26, 108 (1938).

2 Lansing, Phys. Rev., 34, 597 (1929).

3 Beckman, Anna, Diss., Uppsala (1937). 